\title{
Comparison of Adaptive Ant Colony Optimization for Image Edge Identification of Leaves Bone Structure
}

\author{
Febri Liantoni' $^{1}$, Rifki Indra Perwira², Daniel Silli Bataona ${ }^{3}$ \\ ${ }^{1}$ Information Technology, Adhi Tama Institute of Technology Surabaya, Indonesia \\ 2Informatics Engineering, UPN “Veteran” Yogyakarta \\ ${ }^{3}$ Computer technology and network, State Polytechnic of Kupang, Indonesia \\ 1febri.liantoni@itats.ac.id, ${ }^{2}$ rifki@upnyk.ac.id, ${ }^{3}$ danielbataona@pnk.ac.id
}

\begin{abstract}
Leaf bone structure has a characteristic that can be used as a reference in digital image processing. One form of digital image processing is image edge detection. Edge detection is the way toward extricating edge data from an image. In this research, Adaptive Ant Colony Optimization algorithm is suggested for edge image detection of leaf bone structure. The Adaptive Ant Colony Optimization method is a modification of Ant Colony Optimization, in which the initial an ant dissemination process is no longer random, but it is done by a pixel placement process that allows for an edge based on the value of the image gradient. As a comparison also performed edge detection using Robert and Sobel method. Based on the experiments performed, Adaptive Ant Colony Optimization algorithm is capable of producing more detailed image edge detection and has thicker borders than others.
\end{abstract}

Keywords: edge detection, ant colony optimization, robert, sobel.

\section{INTRODUCTION}

Plants are the most substansial item of life on earth. The plant is useful as a supplier of oxygen for breathing, as foodstuff, fuel, medicine, cosmetics and more. The process of grouping plants by identifying the leaf shape image of the plant itself. How to take a leaf image of the plant, it can be done steps recognition of leaf pattern by recognizing the leaf structural characteristics such as the shape and texture of the leaves [1], [2]. Leaf bone structure as one of the features that can differentiate the leaves of various types of plants, because the bone leaves have a unique feature on each type of plant.

The method for processing the input image with the utilization of digital image processing techniques is done to analyze the leaf structural characteristics. Various techniques are developed to facilitate human work, both as image processing, image analyst and image user for various purposes and purposes. Often the image used is not in ideal condition to be studied because of the many disturbances, it can be shadow, photo or picture blur, lack of clarity of object appearance so it can cause problems and influence result and will influence the analysis and plan to be done, hence required 
various technique image processing to obtain the ideal image. One of the usual image processing techniques is edge detection. Edge detection is the way toward extricating edge data from an image. This is viewed as the fundamental advance utilized in most image processing applications. The edges in an image can be considered as the limit between two unique areas [3], [4]. Many approaches have been used to perform edge detection on an image. Some commonly used methods are Prewitt, Roberts, and Sobel [5]. Recent research using Ant Colony Optimization to perform edge detection on images [6].

In this research, edge detection of leaf bone structure practicing Adaptive Ant Colony Optimization method will be finished. The results of Adaptive Ant Colony Optimization method will be compared with conventional edge detection. A comparison process is performed to determine the difference in edge detection results obtained.

\section{RELATED WORKS}

According to Tian et all [7], [8], Ant Colony Optimization is a heuristic technique that imitates ant habits to clear up discrete optimization problems. Ants use special chemical compounds called pheromones to stamp the way between their feed sources and their colonies. The pheromone way is utilized by the next an ant as a reference for food search because pheromones improve the probability of a way to be chosen [9]. There are several advantages of Ant Colony Optimization that can be used to take care of different issues of Non-Polynomial (NP) [7]. Some problems such as traveling salesman problem (TSP), edge detection, algorithm routing, vehicular routing, quadratic assignment problem. In the previous research, ant colony optimization modification has been done by dividing the image into 4 parts first, then the initial ants are divided based on the possibility of the edge in each part of the image. Early ants are still randomly distributed so that edge detection results are still not maximized [3]. In addition, researchers have also used the Ant Colony Optimization algorithm in the preprocess step of mango leaf classification using k-nearest neighbor and support vector machine that method by dividing the image into 4 areas is equal then the ant will be spread by following the number of edge potentials of each area based on the value of the gradient [10].

\section{ORIGINALITY}

In this research, edge detection process that generally uses conventional method will be changed using ant colony optimization method. The method proposed in the process of optimizing the deployment of ants. In general ant colony optimization method, the initial ant positions are haphazardly conveyed, this triggers an irregularity in the appropriation of ants in the pathfinding. Based on the problem, ant distribution modification on ant colony optimization is proposed to optimize ant placement based on a gradient. Ants are not haphazardly conveyed but placed in the highest 
gradient. The so-called adaptive ant colony optimization is expected to be used for better and faster path discovery optimization. This method is a modification of previous research, namely adaptive ant colony optimization, wherein the previous research begins with the image divided by 4 equal parts then the ant spread to determine the edge. whereas in this study the ants were directly spread based on the gradient value.

\section{SYSTEM DESIGN}

In this research, several stages include the selection of image data, preprocess and edge detection. Preprocess stage is done by changing the image of manga leaves into the gray image.

\subsection{Preprocess}

The input data used in the system is the RGB image. From the RGB image information is changed over into a gray image. The process of changing the color image into a gray image using the luminosity technique calculation. The luminosity method is done by calculating the value of each color element $\mathrm{R}, \mathrm{G}$, and $\mathrm{B}$ by adding weight according to the perception of human vision [5]. Human vision is more sensitive to green, therefore $G$ element has the highest weight of other color elements. The calculation of the luminosity method is shown in Eq 1.

$$
\text { Luminosity }=\frac{R 299+G 587+B 114}{1000}
$$

\subsection{Gradient}

Implementation of the magnitude of the gradient is the first step in digital image processing [11]. Gradient values in an area indicate the presence of edges in the area. Gradients are formed over transitions or gradual color changes [12]. For the function $f(x, y)$ in the gradient coordinates $(\mathrm{x}, \mathrm{y})$ is characterized as a two-dimensional section vector with Equation 2.

$$
\nabla f=\left[\begin{array}{l}
G_{x} \\
G_{y}
\end{array}\right]=\left[\begin{array}{l}
\frac{\partial f}{\partial x} \\
\frac{\partial f}{\partial y}
\end{array}\right]
$$

\subsection{Edge Detection using Adaptive Ant Colony Optimization}

Adaptive Ant Colony Optimization algorithm is a heuristic technique that imitates ant habits to clear up discrete optimization problems [7], [13]. Ants use special chemical compounds called pheromones to stamp the way between their feed sources and their colonies. The pheromone path is used by the next an ant as a reference for food search because pheromones increase the likelihood of a path to be selected. In this research selected type of ACS algorithm because this algorithm has applied decrease of pheromone 
concentration, so the possibility of ant trapped in a certain exploration area become smaller [8], [14]. In general, pseudocode is shown in Figure 1.

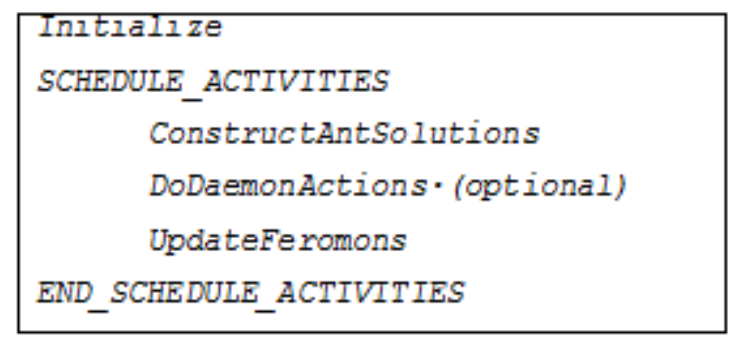

Figure 1. Pseudocode Ant Colony Optimization

Initialize is a step done at the beginning of the process. In this step an initialization procedure is performed, such as setting the parameters and placing the initial pheromone values. The parameters used are the quantity of an ant $(\mathrm{K})$, the quantity of step of construction $(\mathrm{L})$, iteration $(\mathrm{N})$, pheromone evaporation rate $(\rho)$, decay pheromone $(\varphi)$, the weight factor of pheromone $(\alpha)$, and heuristic data weight factor $(\beta)$.

ConstructAntSolutions is a process of traveling from ants. The construction process contains a number of construction measures. Ants will move in an image until the target number of construction steps is formed. In the construction process to $\left(n^{t h}\right)$ the number of ants $\left(k^{t h}\right)$ will move from the neighboring node (i) to the node $(j)$ following the probability displacement $\left(P_{i, j}^{(n)}\right)$. The possibility value is influenced by several factors such as the weight factor of pheromone $(\alpha)$, the heuristic information weight factor $(\beta)$, the pseudorandom proportional rule is shown in Equation 3. Where $(\Omega)$ is the neighboring node of the ant, $(\tau)$ is the pheromone update and $(\eta)$ heuristic information.

$$
P_{i, j}^{(n)}=\frac{\left.\left(\tau_{i, j}^{n-1}\right)^{\alpha}\left(\eta_{i, j}\right)^{\beta}\right)}{\left.\sum_{j \in \Omega_{i}}\left(\tau_{i, j}^{n-1}\right)^{\alpha}\left(\eta_{i, j}\right)^{\beta}\right)} \text { if } j \in \Omega_{i}
$$

DoDaemonActions is a construction solution for additional steps before pheromone value updates. This activity is an additional measure of updating pheromone values. This process can not be done if only by using the number of ants just one (single ant).

UpdateFeromons is a pheromone update activity after the construction and daemon actions are performed. There are two updates, the pheromone global update and the local pheromone update. Local updates of pheromones are carried out each time the construction steps. At this stage, pheromones will be damaged (decay pheromone). It aims to decrease the concentration of pheromones on the edges that are passed. The global update of pheromones is done after the maximum construction step in one iteration is passed. At this stage, there is evaporation of pheromones. The local pheromone update 
is shown in Equation 4. While the global update of pheromones is shown in Equation 5.

$$
\begin{aligned}
& \tau_{i, j}=\left(\begin{array}{ll}
1 & \varphi
\end{array}\right) \tau_{i, j}+\varphi \tau_{0} \\
& \tau_{i, j}=\left(\begin{array}{ll}
1 & \rho
\end{array}\right) \tau_{i, j}+\rho \tau_{i, j}
\end{aligned}
$$

Where $(\tau)$ denotes pheromone updates, $(\varphi)$ shows pheromone deterioration, $(\rho)$ shows evaporation pheromone, $\left(\tau_{i, j}\right)$ represents the total difference of pheromones for global pheromone updates.

In Ant Colony Optimization there is a displacement rule with a probability factor on eight neighboring pixels. This process is calculated using the probability displacement matrix. Pixels with the maximum probability factor in detecting neighbors have edge pixels. To reduce repetitive movements in the ant the rule of stopping criteria is made, ie the displacement of the ant will stop if it passes the path already passed by the other ant and when all pixels of neighbor ( 8 pixels) have been passed by all the ants then the displacement will stop.

In this research, Adaptive Ant Colony Optimization algorithm is chosen to perform leaf image edge detection process. this algorithm is a modified development of ant colony optimization method. The initial ants are dispersed by placing the pixels that have an edge based on the value of the image gradient. The gradient is used to determine the possibility of the edge on the image. Figure 2 is a block of edge detection process diagrams that will be performed using the Adaptive Ant Colony Optimization algorithm. Optimization.

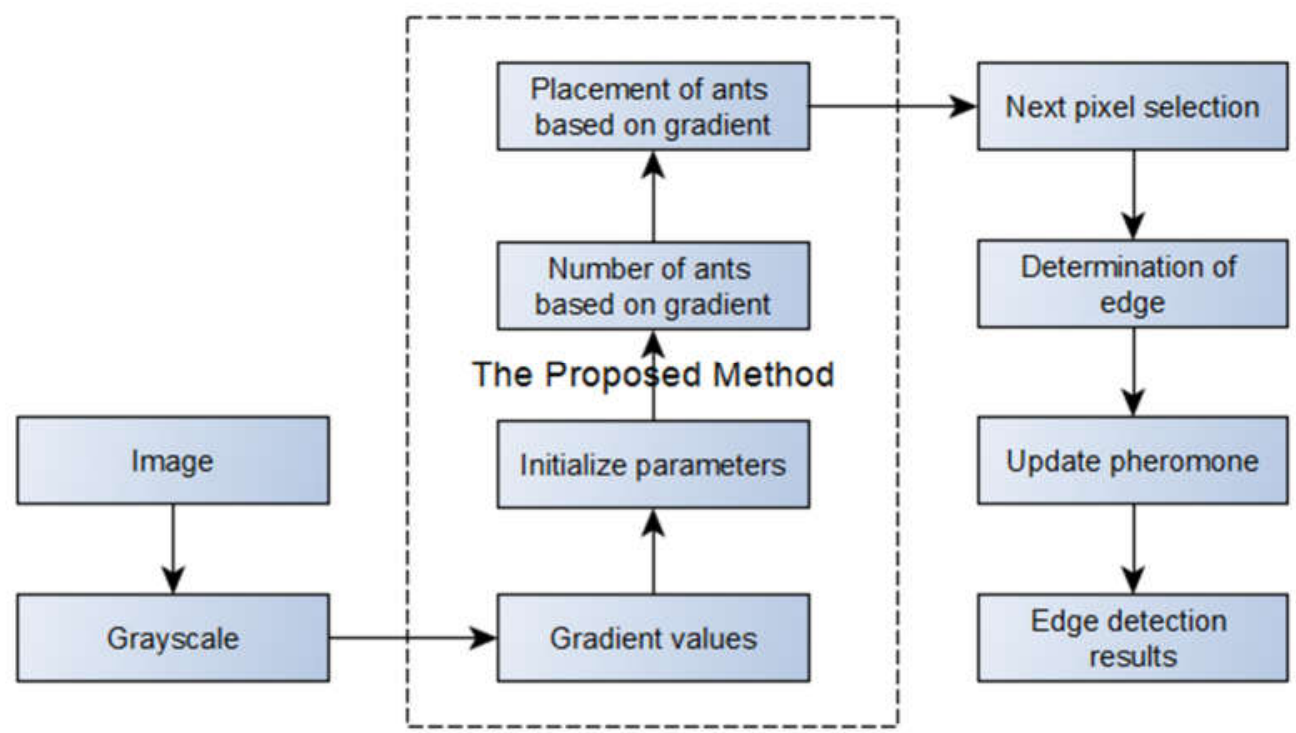

Figure 2. Block diagram of the Adaptive Ant Colony Optimization edge detection process

Some parameters used as Adaptive Ant Colony Optimization algorithm values are shown in Table 1 below. 
Table 1. Test parameters

\begin{tabular}{|c|c|}
\hline Parameters & Nilai \\
\hline $\mathrm{K}$ (number of ant) & $\begin{array}{c}\mathrm{K}=\text { Number of gradients }>= \\
\text { threshold }\end{array}$ \\
\hline L (amount of construction) & 300 \\
\hline$\alpha$ (weighting factor of pheromone) & 1 \\
\hline $\begin{array}{l}\beta \text { (weighted factor of heuristic } \\
\text { information }\end{array}$ & 0,1 \\
\hline$\rho$ (pheromone evaporation) & 0,1 \\
\hline$\varphi$ (pheromone decay) & 0,05 \\
\hline$\tau_{\text {init }}$ (pheromone init) & 0,0001 \\
\hline$\Omega$ (neighboring pixels) & 8 \\
\hline
\end{tabular}

\section{EXPERIMENT AND ANALYSIS}

The test is done at the pre-process stage and classification stage. The results of the preprocessors are used as data at the image edge detection stage. This test purpose to determine the success of the system in the process of image edge detection. Testing is done by comparing the image edge detection results between Adaptive Ant Colony Optimization algorithm with conventional edge detection algorithm. The input image is the RGB image. Image retrieval is performed on a portion of the leaf area, where one example of image capture is shown in Figure 3.

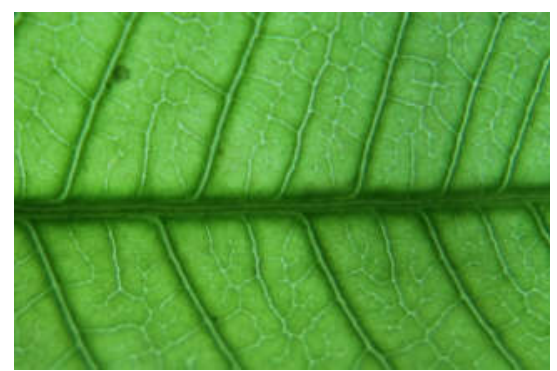

Figure 3. An example of taking a leaf data image

Figure 3 shows the retrieval of leaf image data in a part of the leaf area. It purpose to clarify the texture of the leaf bone so that it does edge detection process. The input image in the form of RGB image is transformed to the gray image. The gray image conversion results are shown in Figure 4.

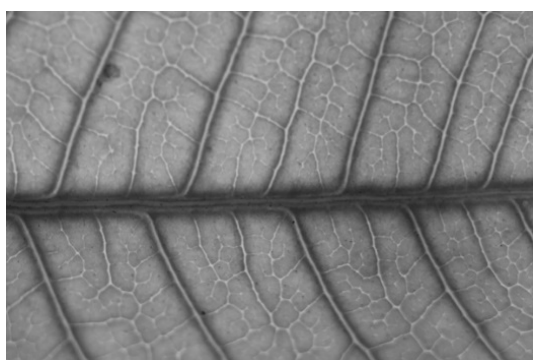

Figure 4. Gray image conversion results 
From the gray image data then done edge detection process. The manga leaf detection trials test was performed using the Adaptive Ant Colony Optimization algorithm and by using conventional edge detection. The outcomes of the edge detection as shown in Figure 5.

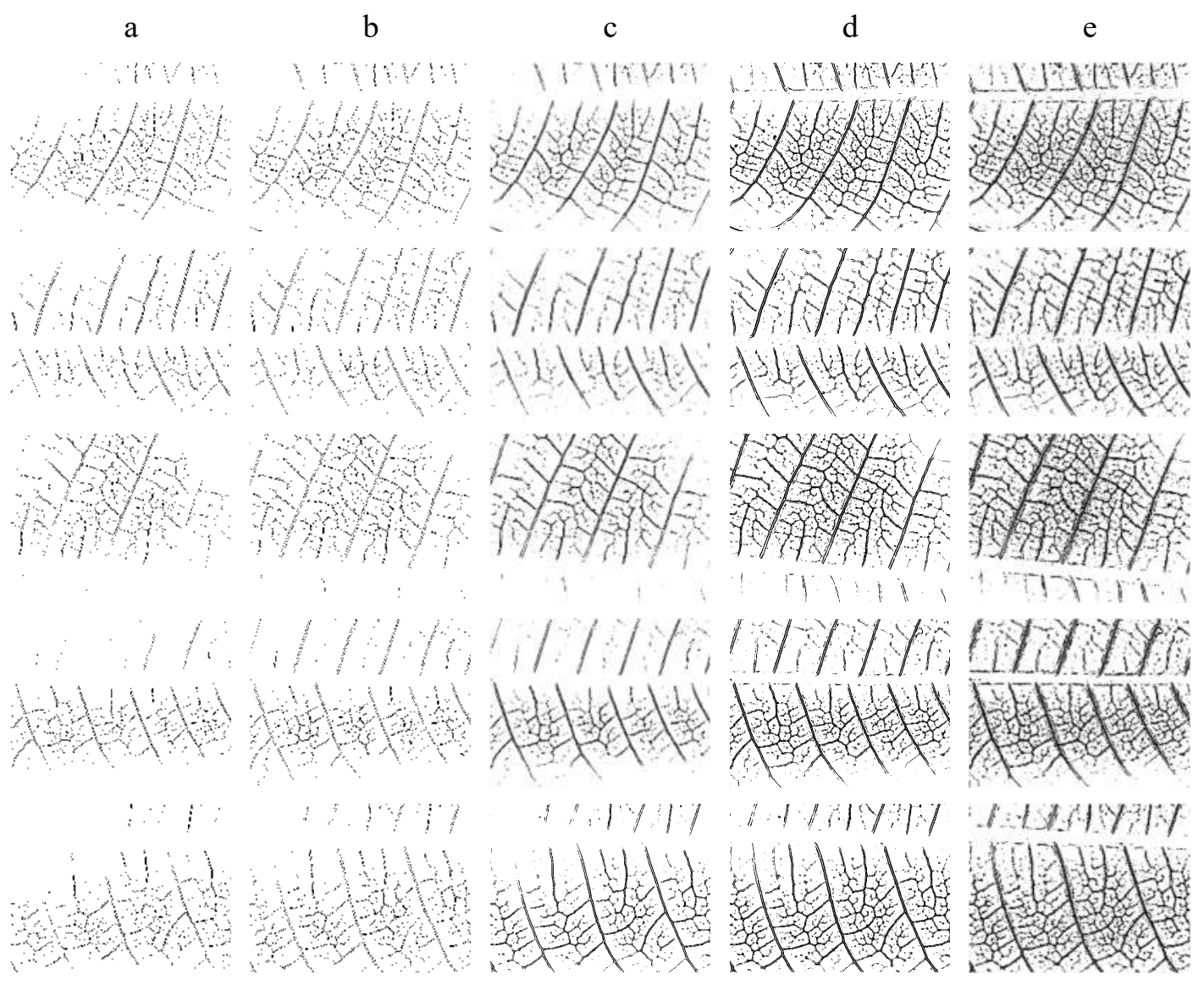

Figure 5. Edge Detection Results, (a) Roberts, (b) Sobel, (c) Ant Colony Optimization, (d) Adapteive Ant Colony Optimization with the division of 4 region image, (e) Proposed method Adaptive Ant Colony Optimization with gradient

Figure 5 shows the Adaptive Ant Colony Optimization algorithm to produce a more detailed image of the bone structure of the bone and has a thicker border. This shows the result of image edge detection using Adaptive Ant Colony Optimization algorithm better than root detection result of Roberts, Sobel and Ant Colony Optimization. The result of the detection of the resulting Robert edge has the worst value compared to other conventional methods because the Robert method uses only two-way filters only. The method proposed by the process of placing ants based on gradients showed a better increase in results compared to the adaptive ant colony optimization method by dividing the 4 regions image carried out in previous studies 


\section{CONCLUSION}

Based on the experiments, it can be concluded that the performance of adaptive ant colony optimization algorithm for edge detection process is able to produce better feature than using Roberts, Sobel and Ant Colony Optimization. Adaptive ant colony optimization algorithm is fit of producing more detailed image edge detection and has thicker borders than others.

\section{REFERENCES}

[1] S. Wu, F. Bao, E. Xu, Y.-X. Wang, Y.-F. Chang, and C.-L. Shiang, "A Leaf Recognition Algorithm for Plant Classification Using Probabilistic Neural Network," in ISSPIT 2007 - 2007 IEEE International Symposium on Signal Processing and Information Technology, 2007.

[2] C. Kalyoncu and Ö. Toygar, "Geometric leaf classification," Computer Vision and Image Understanding, vol. 133, pp. 102-109, Apr. 2015.

[3] F. Liantoni, C. K. Kartika, and H. M. Tri, "Adaptive Ant Colony Optimization based Gradient for Edge Detection," Journal of Computer Science, vol. 7, no. 2, pp. 78-84, 2014.

[4] B. Anna and C. Oppus, "Image Edge Detection Using Ant Colony Optimization," International Journal of Circuits, Systems and Signal Processing, vol. 4, no. 2, pp. 24-33, 2010.

[5] R. Gonzales and R. Wood, Digital Image Processing. Addison Wesley, 1992.

[6] S. Agarwal, "A Review Paper Of Edge Detection Using Ant Colony Optimization," International Journal of Latest Research in Science and Technology, no. 1, pp. 120-123, 2012.

[7] M. Dorigo, M. Birattari, and T. Stutzle, "Ant Colony Optimization: Artificial Ants as a Computational Intelligence Technique," IEEE Computational Intelligence Magazine, 2006.

[8] J. Tian, Y. Weiyu, and X. Shengli, "An Ant Colony Optimization Algorithm For Image Edge Detection," IEEE Congress on Evolutionary Computation, pp. 751-756, 2008.

[9] D.-S. Lu and C.-C. Chen, "Edge detection improvement by ant colony optimization," Pattern Recognition Letters, vol. 29, no. 4, pp. 416-425, Mar. 2008.

[10] F. Liantoni and L. Agus Hermanto, "Adaptive Ant Colony Optimization on Mango Classification Using K-Nearest Neighbor and Support Vector Machine," Journal of Information Systems Engineering and Business Intelligence, vol. 3, p. 75, Oct. 2017.

[11] S. Theodoridis and K. Koutroumbas, "Pattern Recognition," in Pattern Recognition (Fourth Edition), Boston: Academic Press, 2009.

[12] S. Theodoridis and K. Koutroumbas, "Pattern Recognition and Neural Networks," in Machine Learning and Its Applications, 1999, pp. 169-195.

[13] J. Ning, Q. Zhang, C. Zhang, and B. Zhang, "A best-path-updating information-guided ant colony optimization algorithm," Information Sciences, vol. 433-434, pp. 142-162, Apr. 2018. 
[14] O. P. Verma, M. Hanmandlu, S. Kumar, and Dhruv, "A Novel Fuzzy Ant System For Edge Detection," IEEE International Conference on Computer and Information Science, pp. 228-233, 2010. 